\title{
Can indomethacin be helpful in double balloon enteroscopy assisted procedures?
}

We thank Zammit SC et al. [1] for their interest in and comments on our article [2]. In our study, nine of 10 cases complicated by pancreatitis were in patients with suspected sphincter of Oddi dysfunction. These procedures were performed prior to the publication by Elmunzer BJ et al. of the randomized trial of rectal indomethacin to prevent postendoscopy retrograde cholangiopancreatography (ERCP) pancreatitis [3]. In regard to post-oral double balloon enteroscopy (DBE) pancreatitis, in our experience, the incidence was $1.7 \%$ to $2 \%$ $[4,5]$. We noticed that it was more common in patients who were female, of shorter height, and who had a history of prior abdominal surgery [4]. Importantly, we noticed that the incidence was related to the depth of insertion of the DBE [5]. We have encountered virtually no pancreatitis episodes since we stopped pursuing unidirectional oral DBE to reach the cecum in non-ERCP cases.

We are intrigued by the experience shared in the letter where patients who received rectal indomethacin prior to oral DBE appeared to have lower mean amylase levels post-DBE compared to those patients who did not receive it and that the approach might have decreased incidence of clinical pancreatitis [1]. We should point out that the patho- genesis of acute pancreatitis in the DBEERCP setting is likely different from that for DBE done for general purposes in normal anatomy. In Roux-en-Y gastric bypass, the major or minor papilla are not in direct contact with the scope or its balloons, and intestinal pleating is not likely to compress the pancreas or its blood flow. Therefore, evidence of lower amylase levels and reduction in pancreatitis with rectal indomethacin when DBE is performed for common indications may not apply to DBE done to facilitate ERCP. It would be interesting to see if, indeed, rectal indomethacin would decrease clinical pancreatitis in patients undergoing oral DBE in a prospective randomized clinical trial. Meanwhile, we have already used rectal indomethacin in patients who we feel are at higher risk of post-DBE pancreatitis.

\section{Competing interests}

\section{None}

The authors

Laith H. Jamil, Simon K. Lo

Cedars-Sinai Medical Center - Digestive Disease Center, Los Angeles, California, United States
Corresponding author

Laith H. Jamil, MD

Cedars-Sinai Medical Center, Digestive Disease Center, 8700 Beverly Blvd South

Tower - Suite 7706, Los Angeles, CA 90048

Fax: +1-310-423-6554

Laith.Jamil@cshs.org

\section{References}

[1] Zammit SC, Sanders DS, Sidhu R. Can indomethacin be helpful in double balloon enteroscopy-assisted procedures? Endosc Int Open 2019; 7: E730 - E731

[2] Kashani A, Abboud G, Lo SK et al. Double balloon enteroscopy-assisted endoscopic retrograde cholangiopancreatography in Roux-en-Y gastric bypass anatomy: expert vs. novice experience. Endosc Int Open 2018; 6: E885 - E891

[3] Elmunzer B], Scheiman JM, Lehman GA et al. A randomized trial of rectal indomethacin to prevent post-ERCP pancreatitis. N Engl J Med 2012; 366: 1414 - 1422

[4] Basseri RJ, Bucobo JC, Boulay BR et al. W1601: Incidence and imaging characteristics of post-double balloon enteroscopy pancreatitis (post-DBEp). Gastrointest Endosc 2010; 71: AB369

[5] Basseri R, Bucobo JC, Mann N et al. Depth of endoscope insertion is linked to postDBE pancreatitis: 160. Am J Gastroenterol 2010; 105: S60

\section{Bibliography}

DOI http://dx.doi.org/10.1055/a-0839-4624

Endoscopy International Open 2019; 07: E732

(c) Georg Thieme Verlag KG

Stuttgart · New York

eISSN 2196-9736

\section{(요 $\circledast \odot$}

